\title{
Effects of graphite nodules on crack growth behaviour of austempered ductile iron
}

\author{
B. Stokes ${ }^{\text {a }}$, N.Gao, P. A. S. Reed ${ }^{*}$ \\ Materials Research Group, School of Engineering Sciences, University of \\ Southampton, Southampton, SO17 1BJ, UK \\ ${ }^{a}$ Currently at Alaris Medical Systems, Basingstoke, RG22 4BS, UK.
}

Keywords: Austempered ductile iron; Crack growth behaviour; Graphite nodules; Heat treatment

\begin{abstract}
Austempered ductile iron (ADI) is a candidate material for camshafts, where however, the early stages of fatigue damage are of major concern during service. A fundamental microstructurally based assessment of the mechanisms of fatigue failure is important. An ADI microstructure austenitised at $900^{\circ} \mathrm{C}$ and austempered at $390^{\circ} \mathrm{C}$ has been investigated in detail. Crack initiation and growth behaviour was assessed under three-point bend testing conditions. Primary initiation events occurred exclusively at pores with further micro-crack initiation occurring at decohered graphite nodules in the monotonic plastic zone ahead of the advancing dominant macro-crack tip. Lifetime was however determined by propagation behaviour rather than coalescence events. The changes in the as-cast microstructure generated by this heat treatment have resulted in improved fatigue crack propagation performance due to the reduction in eutectic carbides and the relatively high quantity of retained
\end{abstract}

\footnotetext{
"Corresponding author. Tel.: +44-238-059-3763; Fax: +44-238-059-3016

E-mail address: pasr1@soton.ac.uk (P.A.S. Reed)
} 
austenite compared with previous studies, giving rise to greater crack path tortuousity and shielding.

\section{Introduction}

Austempered ductile cast iron (ADI) has attracted considerable interest in recent years because of its excellent properties, such as high strength with good ductility [1,2], good wear [3] and rolling contact resistance [4], and resistance to fatigue $[5,6,7,8]$. The manufacturing cost of ADI is also substantially lower $[9,10,11,12,13]$ than wrought or forged steel. Furthermore, the density of ADI is lower than steel [14]. Thus, ADI has the advantage of higher specific strength than steel [15]. As a result, ADI is considered a very promising engineering material, and an economical substitute for wrought or forged steel in several structural applications in the automotive industry (crankshafts, transmission gears, connecting rods), defence (cannon shells, aircraft landing gears, etc.), earth-moving machinery, railroads, etc. It is these attractive properties that are currently placing ADI as a candidate material for camshaft manufacture. However, due to a demand for improved engine performance, the service conditions for a camshaft in a combustion engine and in advanced engine designs have been changed. This changes the demands placed on the camshaft material, requiring resistance to rolling (as oppose to sliding) fatigue resistance, and high strength and ductility. Contact fatigue is now a significant concern for manufacturers of this type of camshaft and it is clear that both wear and fretting fatigue play an important role. Fretting fatigue is a very situation-specific service problem, and the construction of appropriate tests is extremely complicated. Typically failure [16] is due to the initiation and growth of very small cracks, which leads to 
surface pitting, resulting in further wear-induced failure. Therefore the study of initiation and early growth of cracks and the effect of various microstructural features of ADI on such growth is particularly important, which can provide an insight into the resistance of a microstructure to fatigue damage.

The mechanical properties of ADI can be tailored to suit particular applications by adjusting heat treatment parameters or material compositions. This has the effect of altering the proportions of the major phases present in the microstructure: bainitic ferrite, carbide, high carbon austenite and graphite (in the form of nodules). The process comprises the production of a ductile iron casting, austenitisation (800-950 ${ }^{\circ} \mathrm{C}$ ), subsequent quenching to a temperature, $\left(250-400^{\circ} \mathrm{C}\right)$, suitable for the final stage, the isothermal transformation (austempering) of some of the austenitic matrix to other phases, prior to subsequent cooling to room temperature. The effect of varying both the austenitising and austempering times and temperatures on the short through crack fatigue resistance has been examined on ADI alloys [17]. Austempers of 275, 300, 350,400 and $475^{\circ} \mathrm{C}$ were tested. It was found that the $350^{\circ} \mathrm{C}$ austemper gave the best fatigue crack growth resistance. Austempers of $400,475,300$, and $275^{\circ} \mathrm{C}$, exhibited progressively poorer fatigue crack growth resistance. Austenitising temperatures of 850,900 and $950^{\circ} \mathrm{C}$ under the same austemper were also considered. It was found that the $900^{\circ} \mathrm{C}$ condition gave the best fatigue performance with both the 850 and $950^{\circ} \mathrm{C}$ conditions exhibiting slightly less fatigue crack resistance. No convincing mechanistic explanations in terms of the microstructure were put forward for these observations. Previously we have conducted work on an ADI alloy with four different heat treatment conditions, which consisted of austenitising at 950 or $850^{\circ} \mathrm{C}$ for $1 \mathrm{~h}$ followed by austempering at 250 or $400^{\circ} \mathrm{C}$ for $2 \mathrm{~h}$, denoted: $(950 / 400,850 / 400$, 
950/250, 850/250) [18]. These results have demonstrated that ADI alloys austempered at $400^{\circ} \mathrm{C}$ gave better fatigue crack initiation and growth resistance than those austempered at $250^{\circ} \mathrm{C}$ at similar stress ranges. The toughness ranking was $950 / 400>850 / 400>950 / 250>850 / 250$ indicating that the lower temperature austemper produced a higher hardness, but lower toughness material and the higher temperature austemper generally improved toughness and damage tolerance, but with lower strength/hardness. It was concluded that the coarser lath size and large amounts of retained austenite promoted by the $400^{\circ} \mathrm{C}$ austemper promote a more tortuous crack path, and intrinsic crack shielding [18]. We have also shown that a carbide initiated failure mechanism is dominant for another ADI alloy austenitised at $800^{\circ} \mathrm{C}$ and austempered at $260^{\circ} \mathrm{C}$ due to significant numbers of brittle carbides remaining from insufficient austenitising [19]. Obviously the combination of alloying composition together with the austenitisation and austempering heat treatments, determines the microstructure produced and subsequently the dominant fatigue failure mechanisms [18,20,21]. Linking microstructural models (based on alloy composition and heat treatment parameters) to micromechanistically based models of relevant mechanical properties will provide a much better informed route to alloy optimisation. However detailed micromechanistic understanding of fatigue processes for a full range of possible ADI microstructures is still somewhat lacking. The objective of this research is to explicitly study fatigue initiation and crack propagation in another ADI material austenitised at $900^{\circ} \mathrm{C}$ and austempered at $390^{\circ} \mathrm{C}$ (which is expected to show improved damage tolerance). Particular attention has been paid to the influence of graphite nodules on crack growth behaviour. It is important to understand the early stages of the fatigue process in order to allow development of quantitative performance optimisation criteria. 


\section{Experimental}

An ADI with composition: 3.7C-1.5Si-0.3Mn-1.0Cu-0.5Mo (all numbers are wt.\%) and balance Fe was supplied by Federal Mogul Camshafts as a sand cast block, which subsequently was austenitised at $900^{\circ} \mathrm{C}$ for $1 \mathrm{~h}$ and austempered at $390^{\circ} \mathrm{C}$ for $2 \mathrm{~h}$. A three-point bend set up (Fig. 1) was used for short crack tests which were performed on $12 \times 12 \times 80 \mathrm{~mm}$ cross-section standard bend-bar specimens, in air, at room temperature on a digitally controlled Instron 8501 servo-hydraulic at $5 \mathrm{~Hz}$. A peak opening stress was produced above the centre roller in three-point bend, decreasing to zero above the outer rollers. The maximum applied top surface stresses were 500, 600,700 and $800 \mathrm{MPa}$, at $\mathrm{R}=0.1 ; 800$ and $1100 \mathrm{MPa}$ at $\mathrm{R}=0.5$. The top surface of each bend bar was ground and polished before testing. Etching (using $2 \%$ Nital) of the top surface was used to reveal the matrix microstructure for some specimens. Complete replica records of the specimen top surface were taken at suitable intervals (between 200-1000 cycles) under mean load. This was achieved by softening blocks of acetate in acetone and pressing them onto the top surface of the bend bar. These were then left to harden for about five minutes and were removed for subsequent analysis. From study of the replica record, the number of cracks, their positions and relative lengths were determined as a function of the number of cycles. Measurements of projected crack lengths normal to the tensile axis from the digital images of the acetate replica record were performed using KS 300 on a PC running WinNT. The calculation of $\Delta \mathrm{K}$ was performed using equations as proposed by Scott and Thorpe [22] based on assumptions made for a semi-elliptical short crack. Values of the specimen surface crack tip intensity factor $(K)$ are given by the following equation: 


$$
K_{I}=\left[\left[M_{f 0}\left(1-0.3 \frac{a}{W}\right)\left(1-\left(\frac{a}{W}\right)^{12}\right)\right]+\left[0.394 E(k)\left(\frac{a}{W}\right)^{12} \sqrt{\frac{a}{c}}\right]\right] \frac{\sigma}{E(k)} \sqrt{\pi a}
$$

where the surface correction factor is:

$$
M_{f 0}=\left[1.21-0.1\left(\frac{a}{c}\right)+0.1\left(\frac{a}{c}\right)^{4}\right] \sqrt{\frac{a}{c}}
$$

and the elliptical integral is:

$$
E(k)=\left[1+1.47\left(\frac{a}{c}\right)^{1.64}\right]^{0.5}
$$

where $a$ is the crack depth, $c$ is half the surface crack length and $W$ is the specimen height (as shown in Fig. 1). In order to obtain a more detailed assessment of the interactions between the propagating crack and the matrix microstructure, a number of short fatigue crack tests were interrupted after a chosen number of cycles. The specimens were then removed from the testing apparatus and subsequently analysed in detail using a FEG SEM. In order to investigate the effect of specimen microstructure on crack propagation under well defined stress states, a number of three-point bending long fatigue crack tests were performed on single-edge notchedbend (SENB) bars with a pre-existing slot of an $\mathrm{a} / \mathrm{w}=0.25$. The notch was sharpened with a razor blade to promote crack initiation. Long crack growth behaviour was established by load shedding down to threshold (da/dN $\sim 10^{-8} \mathrm{~mm} /$ cycle) in $10 \%$ steps in $\Delta \mathrm{K}$, each load shedding step was preceded by growth through 4 monotonic plastic zone sizes at constant $\Delta \mathrm{K}$ levels. Thresholding was followed by growth of the crack under constant load and increasing $\Delta \mathrm{K}$ conditions until fast fracture occurred. The final $K_{\max }$ value achieved prior to final failure was taken to be an approximation of the cyclic $\mathrm{K}_{\mathrm{Q}}$ value of the material. Crack length was monitored by conventional D.C.P.D. techniques. 


\section{Results}

\subsection{Microstructure}

The matrix microstructure generally consists of coarse bainite laths, large blocky pools of retained austenite and graphite nodules (Fig. 2). The near total absence of carbide structures present in the as-cast microstructure in the microstructure indicates that the austenitising temperature of $900^{\circ} \mathrm{C}$ is sufficient to cause their dissolution. However, the bainite structure is far from homogeneous. During the austempering, the nucleation of bainite occurs at the graphite/austenite interface [23] and grows by sympathetic nucleation of further plates into the austenite. At the same time, the growing bainite rejects carbon into the austenite. Due to the growth of bainite sheaves away from the graphite, these regions of supersaturated austenite exist in areas remote from nodules. Hence, for a conventional ADI alloy, as the distance from the graphite nodules increases, the proportion of austenite increases. However, in this case, there are large regions free of blocky austenite pools, the location of which appears unrelated to that of graphite nodules.

\subsection{Short fatigue crack testing}

Thirteen short fatigue crack tests have been conducted within the 500-1100 MPa maximum applied stress testing range. Typical fatigue behaviour is observed where increasing lifetime is observed with a decrease in applied stress (Fig. 3). Failure occurred at approximately 28000,46300 and 70200 cycles for $\mathrm{R}=0.1$ tests with 
respectively a maximum applied stress of 800,700 and $600 \mathrm{MPa}$. It is particularly noteworthy that no failure occurred when a specimen was tested at a maximum stress of $500 \mathrm{MPa}$ with an R-ratio of 0.1 . High R-ratio tests $(\mathrm{R}=0.5)$ were also performed on the specimens. No failure was observed after 10 million cycles for a specimen tested at a maximum stress of $800 \mathrm{MPa}$. Further $\mathrm{R}=0.5$ tests were therefore carried out at higher maximum stress levels. Failure occurred at approximately $32000-43000$ cycles for $\mathrm{R}=0.5$ tests with a maximum applied stress of $1100 \mathrm{MPa}$. When this is considered in terms of applied stress range it becomes apparent that these $\mathrm{R}=0.5$ tests with a stress range of $550 \mathrm{MPa}$ exhibited shorter lifetimes than $\mathrm{R}=0.1$ tests with a stress range of $630 \mathrm{MPa}$. This implies that lifetime is dependent on absolute stresses as well as applied stress range, with shorter lifetimes being shown for higher overall stresses and higher applied stress range. No further $\mathrm{R}=0.5$ tests were performed since it was identified that $\mathrm{R}=0.1$ was more representative of the service condition.

\subsubsection{Crack initiation and propagation}

Initiation of the dominant fatigue cracks occurred exclusively at pores, present either on the surface (Fig. 4a) or immediately below (Fig. 4b). In general, these pores are angular in morphology and hence act as significant stress raisers. Evidence of initiation was present on the first replica for all tests performed at an R-ratio of 0.1 suggesting a rather easy initiation stage seemingly not affected by magnitude of applied stress. Further initiation events occurred ahead of the propagating dominant crack tip throughout the lifetime of the specimen. Initiation occurred at decohering graphite nodules (see Fig. 4c regions B to F). 
Not all of these micro-cracks coalesced with the advancing dominant crack, and crack interactions were limited to events following initiation events ahead of the advancing dominant crack tips. Typically the formation of one or two large fatigue cracks was observed which ultimately coalesced at final specimen fracture. Decohesion of graphite nodules and subsequent initiation and growth of micro-cracks may lead to deflection of the dominant crack system as they approach coalescence. Region A in Fig. $4 \mathrm{c}$ is a particularly good example. Fig. 5 shows the dominant crack paths at $90 \%$ life for the polished fatigue crack test samples at 800,700 and $600 \mathrm{MPa}$ respectively. Greater deflection is shown by the dominant crack as applied stress is increased. The projected length of the largest crack as a function of number of fatigue cycles has been plotted for specimens tested at an R-ratio of 0.1 in Fig. 6a. Crack growth rate is faster for tests performed at higher values of applied stress at comparable crack lengths (Fig. 6b). The rather erratic crack growth shown by the specimen tested at 800 $\mathrm{MPa}$ is a direct result of the coalescence events from the dominant macro-crack. This macro-crack was formed by the coalescence of approximately 16 micro-cracks. The number of micro-cracks coalescing to form the dominant macro-crack for the 700 MPa test was far fewer, only 6; and the $600 \mathrm{MPa}$ test suffered no coalescence events before final fracture.

\subsubsection{The influence of graphite nodules on crack propagation}

To examine more quantitatively the influence of graphite nodules on ADI fatigue crack propagation and the extent of graphite nodule/crack interaction, the number of nodules present along the crack path have been counted at approximately $90 \%$ of the total lifetime using replica records. At the same time, to assess whether the advancing fatigue cracks were 'seeking out' graphite nodules, these data were compared to the 
number of nodules intercepted by simulated 'straight cracks' of equivalent length. This has been done by placing thirty random lines of equal length to the fatigue crack at $90 \%$ life on images of each specimen to simulate non-deflected crack growth. It can be seen from Table 1 that there is a significant increase in the frequency of graphite nodules along the crack path as the applied stress levels are increased. It is also clear for the tests performed at $800 \mathrm{MPa}$ and $700 \mathrm{MPa}$ that the crack path intercepts significantly more graphite nodules than the equivalent non-deflected crack. An increase of at least two hundred percent was observed for both tests. The dominant crack for the test performed at $600 \mathrm{MPa}$ intercepted no more nodules than the simulated non-deflected cracks. Table 1 shows that $47 \%$ of the graphite nodules along the dominant crack path initiated ahead of the crack at $800 \mathrm{MPa}$. This compares to $25 \%$ and $14 \%$ for the tests performed at $700 \mathrm{MPa}$ and $600 \mathrm{MPa}$ respectively.

The number of graphite nodules as a function of dominant crack length was also investigated. The data is presented in Fig. 7a together with the 'simulated nondeflected' cracks for comparison. It is apparent that the data for both the $800 \mathrm{MPa}$ and the $700 \mathrm{MPa}$ specimens deviates from the respective 'simulated non-deflected' cracks. At corresponding crack lengths greater than $0.5 \mathrm{~mm}$, significantly more graphite nodules had been intercepted by the dominant crack than the 'non-deflected' crack. Furthermore, the $800 \mathrm{MPa}$ test exhibited more graphite nodules on the dominant crack than the $700 \mathrm{MPa}$ test. However, the 'non-deflected' cracks for these two specimens showed a similar trend. The data from the dominant and 'nondeflected' cracks in the $600 \mathrm{MPa}$ specimen is comparable, suggesting minimal influence of graphite nodules on crack propagation. This analysis was extended to determine the effect of $\Delta \mathrm{K}$ on the number of graphite nodules on the dominant crack 
path. These are again compared to the 'simulated non-deflected' cracks for the corresponding specimen (Fig. 7b). It is clear that above a $\Delta \mathrm{K}$ of $20 \mathrm{MPa} \sqrt{\mathrm{m}}$ the number of nodules on the dominant crack path exceeds that on the 'simulated nondeflected' cracks for both the $800 \mathrm{MPa}$ and $700 \mathrm{MPa}$ specimens. At lower values of $\Delta \mathrm{K}$, the dominant cracks intersect fewer graphite nodules than the 'non-deflected' crack. It is probable that this reflects the initiation of the dominant cracks from porosity. No such restriction exists for the 'simulated non-deflected' cracks.

The mechanisms of crack propagation within the matrix microstructure between graphite nodules in porosity initiated short cracks were investigated during interrupted tests. Both deflected and non-deflected short fatigue crack growth has been observed. Microstructural features that have been observed to cause crack deflection include: graphite nodules, the interface between retained austenite and bainite, and bainite packets. These features do not cause crack deflection on every occasion however. Figure 8 shows high magnification images of an interrupted short crack test. Propagation along the interface between bainite and retained austenite causing significant crack deflection can be seen in the top of region A. In the centre of region A, the crack appears to have propagated around the perimeter of a bainite packet. In region B the crack can be seen to deviate in order to impinge on a graphite nodule. Several examples of crack propagation through pools of retained austenite are visible in region $\mathrm{C}$.

\subsection{Long fatigue crack testing}


Long fatigue crack testing has identified values of $\Delta \mathrm{K}_{\text {th }}$ (threshold) and $\mathrm{K}_{\mathrm{Q}}$ (nominal cyclic toughness). The value for fatigue threshold $(8.0 \mathrm{MPa} \sqrt{\mathrm{m}})$ for the current heat treatment is higher than that of the as-cast ductile iron $(6.0 \mathrm{MPa} \sqrt{\mathrm{m}})$ whilst values of $\mathrm{K}_{\mathrm{Q}}$ seem highly variable (from 24 to $32 \mathrm{MPa} \sqrt{\mathrm{m}}$ ) [24]. Fatigue threshold and constant load amplitude growth out tests allow the observation and comparison of fracture surfaces corresponding to varying values of $\Delta K$ (Fig. 9). Decohered graphite nodules are highly visible and are present at all values of $\Delta K$. The fracture surface at lower values of $\Delta \mathrm{K}$ and those approaching threshold show quite differing features to the higher $\Delta \mathrm{K}$ images. At the lower $\Delta \mathrm{K}$, some brittle facets, perhaps representing occasional cracked eutectic carbides are visible. As $\Delta \mathrm{K}$ increases the fracture surface images suggest an increase in surface roughness. The long fatigue crack data have been plotted with the data from the short crack test which showed the least number of coalescence events at a maximum stress of $600 \mathrm{MPa}$ (Fig. 10). It is apparent that the short crack test data merges with the long crack regime at values of $\Delta \mathrm{K}$ above 14 $\mathrm{MPa} \sqrt{\mathrm{m}}$. This represents short cracks with lengths in the order of $620 \mu \mathrm{m}$. It is also noticeable that the short crack grows, with 'classic' short fatigue crack behaviour, at values of $\Delta \mathrm{K}$ below the long crack threshold and faster crack growth rates at comparable values of $\Delta \mathrm{K}$.

\section{Discussion}

\subsection{Microstructure}

The mechanical properties of ADI vary over a wide range of values, mostly controlled by microstructural factors [25]. Some of these factors depend on heat treatment, as in 
the case of phases present (quantity, size and distribution). Others may be related to solidification, such as graphite nodules (number, size and shape), and defects (porosity, inclusions, segregated elements, second phase particles or unwanted eutectics) [26]. In general, the microstructural factors that contribute to a loss of toughness are: reduction in percentage nodularity, high percentage or continuity of intercellular or interdendritic carbides, and microporosity. For the current ADI microstructure the matrix itself is formed by two main constituents (retained austenite and bainite). Since retained austenite is a softer phase than bainite the hardness values are quite different. Graphite nodules are comparatively very soft and they have a significantly lower effective Young's modulus than the surrounding matrix, decohere easily and may be considered to act as holes in a mechanical sense.

One of the most important factors in determining the mechanical properties of the final ADI component is the relative volume fraction $\left(\mathrm{V}_{\mathrm{f}}\right)$ of retained austenite $(\mathrm{RA})$ and bainite present in the matrix, and their associated carbon concentrations. In general, tensile strength and hardness decrease as the $V_{f}$ of RA increases (and that of bainite decreases) [7]. The amount of bainite in ADI as a function of composition and heat treatment parameters has been predicted on the basis of the limiting carbon content for diffusionless transformation by using thermodynamic and kinetic theory $[24,27,28]$. The predicted result is that the matrix microstructure contains $44.5 \%$ retained austenite and $46.4 \%$ bainite at the current austempering condition.

\subsection{Crack initiation}


Primary crack initiation in the microstructure occurred exclusively at pores, either surface or sub-surface. The number of primary initiation sites has a profound impact on the mechanism of failure and ultimately the lifetime of the specimen. For the interval tests performed at an R-ratio of 0.1 , cracks were observed on the first interval acetate replica. This would indicate a rather easy initiation stage for all microstructures and suggest primary initiation is dependent on local microstructure rather than the maximum applied stresses. Additionally, micro-crack initiation events were observed throughout the lifetime and appeared dependent on one or more of the following: microstructure, load ratio and stress range. The angular nature of the crack initiating pores clearly provide points of stress concentration. Other authors $[29,30,31]$ have observed initiation of this type. It is suggested that in the absence of pores and other such defects, primary initiation occurs at graphite nodules [21].

In this ADI material secondary crack initiators were graphite nodules. Decohesion of the interface between the graphite nodules and matrix is likely to be caused by mechanical property mismatch occurring in the stress field ahead of the advancing crack, leading to the subsequent initiation of micro-cracks. Greno et al. [31] identified the irregular surface of the graphite-matrix interfaces (sharp micro-notches) as high stress concentrators. These act as preferential initiation sites in the increased $\Delta \mathrm{K}$ region in the vicinity of the advancing crack tip. Further tests at progressively lower maximum stresses showed fewer crack initiation events ahead of the crack tip. As a direct result there were fewer coalescence events visible for these specimens until the failure mechanism was almost exclusively propagation controlled. It is reasonable therefore to suggest that decohesion and subsequent crack initiation is in fact sensitive to the crack tip stress intensity factor and hence the locally raised stress field 
experienced by the graphite nodules, fitting in with previous observations [31]. The plastic zone ahead of the advancing crack increases with increasing stress intensity factor. The larger the plastic zone ahead of the crack tip, the greater number of graphite nodule interfaces will be subjected to the increased stress and strain values associated with this region.

The location of micro crack initiation events with respect to the advancing dominant crack tip has been investigated for the fatigue crack tests performed at an applied stress of 800 and $700 \mathrm{MPa}$. Both the distance of the initiation event from the crack tip and angle of inclination were considered [24]. Estimations of monotonic and cyclic plastic zone sizes $\left(r_{y}\right)$ were made using the following equations [32]:

$$
\begin{array}{ll}
\text { Monotonic: } & r_{y}=\frac{1}{4 \pi}\left(\frac{K_{\max }}{\sigma_{y}}\right)^{2}\left[1+\cos \alpha+\frac{3}{2} \sin ^{2} \alpha\right] \\
\text { Cyclic: } \quad r_{y}=\frac{1}{4 \pi}\left(\frac{\Delta K}{2 \sigma_{y}}\right)^{2}\left[1+\cos \alpha+\frac{3}{2} \sin ^{2} \alpha\right]
\end{array}
$$

where $\sigma_{y}$ is the yield stress taken from predictions based on the relative properties and amounts of the major matrix constituents [27]. Equations (4) and (5) consider the size and shape of the plastic zone with regards to the angle of inclination $(\alpha)$ from the crack tip. The redistribution of stress due to plasticity however, is not taken into account in estimating the extent of plastic zone size. Fig. 11 compares the size of monotonic and cyclic plastic zones at the tip of the advancing dominant macro-crack 
and the proximity of near tip micro-crack initiation events. All data points below the $\mathrm{x}$ $=\mathrm{y}$ line indicate where micro-crack initiation occurred within the crack-tip plastic zone. It has been estimated that $83 \%$ of all near-tip initiation events occurred within the monotonic plastic zone and only $17 \%$ within the cyclic plastic zone, implying that initiation ahead of the crack tip mostly occurs within the monotonic crack-tip plastic zone. This indicates that graphite nodule decohesion does not require globally reversed plasticity to occur, although the local stress state around the nodules is likely to be complex.

\subsection{Crack propagation}

As identified in Fig. 7a the number of graphite nodules on the dominant crack with a microstructure appears to decrease with a corresponding decrease in the applied stress level. When compared to the 'simulated non-deflected cracks' it is clear that the dominant crack for tests at $800 \mathrm{MPa}$ and $700 \mathrm{MPa}$ intersected a greater number of graphite nodules. This suggests that at these stress levels, the dominant crack was 'seeking' out graphite nodules, which provide the lowest energy path in linking [29]. Identification of whether all these graphite nodules decohered ahead of the crack-tip before intersection was prevented by the frequency of the replica records for these tests. The data summarised in Table 1 shows that for the test performed at $800 \mathrm{MPa}$, only $47 \%$ of the graphite nodules on the crack profile were seen to decohere ahead of the crack-tip. This falls to $25 \%$ for the test performed at $700 \mathrm{MPa}$. It is expected however, that these figures are an underestimation, with the decohesion of graphite nodules, micro-crack initiation and subsequent coalescence occurring in the period between replicas. The test performed at $600 \mathrm{MPa}$ showed no increase in the number 
of graphite nodules intersected by the dominant crack over the 'simulated nondeflected crack'. This would suggest that the path of the dominant crack was not influenced by graphite nodules at this lower stress level. The lower number of coalescence events before fracture for the $600 \mathrm{MPa}$ maximum stress test may be the reason for the relatively stable crack growth rates shown for this specimen in Fig. 6 b. It is also reasonable to suggest that the lower number of initiation events and subsequent crack coalescence is responsible for the less deflected dominant crack path shown in Fig. 5.

Fig. $7 \mathrm{~b}$ suggests the number of graphite nodules intercepted by a dominant crack is controlled by $\Delta \mathrm{K}$. At values of $\Delta \mathrm{K}$ above $20 \mathrm{MPa} \sqrt{\mathrm{m}}$ the dominant crack intercepts a greater number of graphite nodules than the corresponding 'simulated non-deflected cracks'. At lower values of $\Delta \mathrm{K}$ fewer initiation events are observed ahead of the crack tip. Furthermore, observation of fatigue crack fracture surfaces shows increased numbers of graphite nodules and surface roughness with increasing values of $\Delta \mathrm{K}$. It is reasonable to suggest this reflects the increase in size of monotonic crack tip plastic zone associated with increasing $\Delta \mathrm{K}$. More graphite nodules will be encompassed by the plastic zone effectively giving the crack tip a greater 'sampling area'. The greater extent of the near tip plastic zone is likely to increase the probability of graphite nodule decohesion and micro-crack initiation ahead of the crack-tip and in turn, subsequent deflection of the dominant crack by coalescence events. Therefore, it is reasonable to propose higher stress intensity factors cause the advancing dominant crack to 'seek out' graphite nodules. This may cause increased crack deflection and fracture surface roughness and consequently may decrease global crack growth rates by roughness induced closure mechanisms and shielding effects [33]. It has been 
proposed that as microcracks simultaneously propagate besides the main crack, the available elastic energy for the propagation of the main crack is diminished mainly because of the creation of a larger crack surface [34]. In addition there is growing evidence of the shielding effect that microcracking has on the tip of a dominant macrocrack, redistributing and reducing the average near-tip stresses [35]. Sources of stress redistribution are the reduction of elastic moduli resulting from microcracking and inelastic strains arising from the release of residual or transformation stresses when microcracks are formed. The above-mentioned mechanisms provide evidence to explain the relatively low propagation rates and high effective propagation threshold values of ADI when compared with those of steels [34].

Investigation of the mechanism of micro-crack initiation ahead of the advancing crack tip has been conducted by means of a $2 \mathrm{D}$ elastic computational model developed using the boundary element method [31]. A graphite nodule was modelled as having nucleated micro-cracks fore and aft with respect to the dominant crack at varying positions along the nodule perimeter. Stress intensity factors were calculated for the dominant crack and the micro-cracks nucleated from the graphite nodule. It was found that the effect of interaction between crack and nodule is more marked for the microcracks emanating from graphite nodules than for the dominant crack with the greatest increase observed for the micro-crack facing the dominant crack. The value of stress intensity factor for this crack increases ten-fold and approaches that of the dominant crack. The crack facing away from the dominant crack showed an increase in stress intensity factor, although to a lesser extent. Predictably, the nearer the nodule to the dominant crack tip, the greater the increase in stress intensity factor. It was also shown that the angular position of the graphite nodule with respect to the dominant 
crack-tip has only a minor influence on any increase in stress intensity factor. It was noticed in the present study that crack initiation from the interface between graphite nodules and matrix occurred at various orientations around the graphite nodule. The orientation of crack initiation from graphite nodules with respect to the nodule has been measured and is summarised in Fig. 12. It suggested that the majority of crack initiation events facing the advancing dominant crack tip occur at an orientation of 15 to 30 degrees from the tensile axis. This is in good agreement with the work of Greno et al. [31] who investigated the effect of crack initiation from various orientations around the graphite nodule $(\theta)$. They pointed out that the greatest increase in stress intensity factor for micro-cracks initiating and propagating towards the dominant crack occurred when $\theta$ is also between 15 and 30 degrees. The increase in stress intensity factor for micro-cracks initiating and propagating in the same direction as the dominant crack was less pronounced and varied less with $\theta$. There is a greater variability in orientation for micro-cracks that initiated and propagated in the same direction to the dominant crack [31]. Not all micro-cracks initiating from decohered nodules coalesce with the advancing dominant macro-crack. It is not clear at the present time why one crack should coalesce with the dominant crack whilst another does not. It is possible that the matrix microstructure between two cracks and the crack spacing are significant factors in selecting coalescence events.

Three dimensional FE models produced by Soboyejo et al. [36] on pairs of coalescing cracks in steels have predicted parallel offset non-coplanar semi-elliptical cracks would grow independently until adjacent crack tips overlap. Subsequent growth in the region of overlap is associated with deviations of the adjacent crack tips. The deviations do not appear to significantly affect crack growth outside the region of 
overlap. Similar behaviour for parallel offset non-coplanar cracks was observed in this study. The deviation of the adjacent crack tips is clear for crack A and crack B in Fig. 13. Furthermore, any deviation does not appear to take place until the adjacent crack tips overlap. Fig. 14a shows the crack-tip separation and overlap compared with the crack growth rates respectively of the two cracks in Fig. 13. Reducing crack-tip separation appears to have little effect on crack growth rate. Soboyejo et al. suggested offset cracks may coalesce at depth positions without coming into contact at the surface. Additionally, it is suggested in the literature that there is a sudden increase in stress intensity factor as cracks coalesce $[37,38]$. The high stress intensity factors in the region of coalescence result in a rapid transition to a semi-elliptical crack. The stress intensity factor then decreases as the crack forms a semi-elliptical shape $[37,38]$.

Microstructural features such as the boundaries between prior austenite grains in the so-called "ausferrite" microstructure were observed to significantly retard the propagation of a short fatigue crack, owing to the additional requirement to tilt and twist the crack plane for crystallographic propagation into the next grain $[39,40]$. Boundaries between "ausferrite" (bainite) packets (shown in the centre of region A of Fig. 8) have been observed to retard and arrest the propagation of cracks by blocking planar slip along the austenite $\{111\}$ plane $[40,41]$.

\subsection{Comparison with other heat treatment conditions}

\footnotetext{
† The authors believe "ausferrite" to be a common misnomer in the ADI field, where "ausferrite" is simply upper or lower bainite.
} 
The number of fatigue cycles to failure of the same ADI material austenitised at $800^{\circ} \mathrm{C}$ and austempered at $260^{\circ} \mathrm{C}$ ('800/260') in a previous study [19] has been compared with the current results ('900/390') in Fig. 3. Only a small percentage of the ' $800 / 260$ ' specimens show comparable fatigue lifetimes and the majority have shorter lifetimes than the '900/390' condition at comparable stress levels. The short crack data for both heat treatments have also been plotted compared in Fig. 10, demonstrating that short cracks in the ' $800 / 260$ ' material exhibit faster crack growth rates than in the '900/390' condition. In addition, very different mechanisms of short fatigue crack initiation were observed for the material in each heat treatment condition. The ' $800 / 260$ ' material contained numerous eutectic carbides retained from insufficient austenitisation and cracked carbides formed a prolific source of micro-crack nucleation sites in the ' $800 / 260$ ' condition. However, in the ' $900 / 390$ ' heat treatment, which was predominantly free of eutectic carbides, initiation of the fatigue crack occurred at pores, of which there were far fewer. Secondary initiation occurred at graphite nodules and it may be supposed that in the absence of pores these would act as crack initiation points, albeit after a greater number of cycles. The variable distribution of the carbide structures throughout the ' $800 / 260$ ' microstructure produced a range of fatigue failure behaviour from coalescence to propagation dominated failure, whereas fatigue in the '900/390' material was largely propagation dominated. The mechanism of failure has a distinct effect upon the specimen lifetime. Generally speaking, the greater the extent of crack propagation (i.e. the less coalescence events), the longer the lifetime of the specimen. However, a limited number of coalescence events directly attributable to initiation ahead of the crack tip may lead to extended fatigue life by creating a more tortuous crack path, leading to 
increased crack tip shielding, due to both reduced local crack tip stress intensities and possible roughness induced closure effects.

The comparative propagation behaviour in the as-cast ductile iron, the '900/390' and ' $800 / 260$ ' heat treatments has been assessed using long crack fatigue testing, shown in Fig. 14b. Crack growth rates for the as-cast ductile iron and ' $800 / 260$ ' are generally faster than the ' $900 / 390$ ' for comparable values of $\Delta K$ (the propagation data for these two alloy conditions lie in the upper range of the '900/390' scatter band). This means that the changes in the as-cast microstructure generated by the ' $900 / 390$ ' heat treatment have resulted in improved fatigue crack propagation performance. No such improvement was promoted by the '800/260' heat treatment. The '900/390' heat treatment is tougher and has a higher fatigue threshold than the other two variants. The improvement in toughness may be due to the lack of eutectic carbides and the relatively high quantity of retained austenite in the '900/390' microstructure. Previous workers $[42,43]$ have observed that blocky regions of austenite near the crack tip in similar austempered irons undergo martensitic transformation under the influence of the local crack tip stress state. This should give rise to a transformation toughening effect that effectively lowers local crack tip stresses due to the local volume change from the phase change, improving both fracture toughness and propagation resistance (with an additional effect of increased closure due to the local volume increase at fatigue threshold). It is also likely that the greater number of brittle eutectic carbides in the ' $800 / 260$ ' heat treatment decrease the toughness of a microstructure by increasing the proportion of static failure modes [24]. The long fatigue crack tests have identified crack deflection by bainite sheaves at near threshold values of stress intensity factor. Other authors $[23,27,44]$ have noticed a retained austenite film 
surrounding bainite sheaves. It is possible this ductile film provides a sufficient barrier to cause crack deflection at these low values of $\Delta \mathrm{K}$. It is believed this feature causes roughness induced crack closure and therefore is another possible factor responsible for the elevated fatigue threshold compared to the as-cast ductile iron and the ' $800 / 260$ ' heat treatment.

\section{Conclusions}

1. An ADI microstructure austenitised at $900^{\circ} \mathrm{C}$ and austempered at $390^{\circ} \mathrm{C}$ has been investigated and compared to results in the literature. Initiation of the dominant fatigue cracks occurred exclusively at pores, present either on the surface or immediately below. Further initiation events (confined to graphite nodules within the crack-tip monotonic plastic zone) occurred ahead of the propagating dominant crack tip throughout the lifetime of the specimen. However the lifetime was principally propagation rather than coalescence dominated.

2. Decohesion of graphite nodules and subsequent initiation and growth of microcracks may lead to deflection of the dominant crack system as they approach coalescence. The number of micro-cracks coalescing to form the dominant macrocrack increases with increase in applied stress levels, leading to greater overall crack path tortuosity, and possible shielding effects.

3. The number of graphite nodules intercepted by a dominant crack is a factor of $\Delta K$. At values of $\Delta \mathrm{K}$ above $20 \mathrm{MPa} \sqrt{\mathrm{m}}$ the dominant crack intercepts a greater number of graphite nodules. The greater extent of the near tip plastic zone is likely to increase 
the probability of graphite nodule decohesion and micro-crack initiation ahead of the crack-tip.

4. The changes in the as-cast microstructure generated by this heat treatment have resulted in improved fatigue crack propagation performance. This is due to the lack of eutectic carbides and the relatively high quantity of retained austenite in the microstructure. Near threshold, greater deflection at bainite sheathes is observed and this is believed to give rise to greater roughness induced closure and to improved near-threshold performance.

\section{Acknowledgements}

Materials and financial support from Federal-Mogul Camshafts and EPSRC Grant No GR/M13879 are gratefully acknowledged. 


\section{References}

1 J. Dodd, Mod. Cast. 68 (1978) 60.

2 R.B. Gundlach, J. F. Janowak, AFS Trans. 94 (1983) 377.

3 I. Schmidt, A. Schuchert, Z. Met. 78 (1987) 871.

4 N. Rebasa, R. Dommarco, J. Sikora, Wear 253 (2002) 855.

5 M. Johansson, AFS Trans. 85 (1977) 117.

6 L. Bartosiewicz, A.R. Krause, F.A. Alberts, I. Singh, S.K. Putatunda, Mater. Character. 30 (1993) 221.

7 P. Shanmugam, P.P. Rao, K.R. Udupa, N. Venkataraman, J. Mater. Sci. 29 (1994) 4933.

8 L. Bartosiewicz, S. Duraiswamy, A. Sengupta, S.K. Putatunda, In: Morris Fine Symposium, TMS, Detroit, MI, 1991, pp. 135-138.

9 L. Bartosiewicz, A.R. Krause, A. Sengupta, S.K. Putatunda, In: International Symposium for Testing and Failure Analysis, ISTFA, ASM 16, 1990, pp. 323336.

10 G. Wilkinson, C. Grupke, In: 2nd International Conference on Ductile Iron, Ann Arbor, MI, 1986, pp. 349-358.

11 J. Panasiewicz, C. Grupke, J. Huth, In: World Conference on Austempered Ductile Iron, Bloomingdale, IL, 1991, pp. 176-194.

12 K. Okazaki, H. Asai, M. Tokuyoshi, H. Kusonoki, H. Sakahara. In: Proceeding World Conference on Austempered Ductile Iron, Bloomingdale, IL, 1991, pp. 288-299.

13 B.V. Kovacs, Mod. Cast. 36 (1990) 38.

14 T. Shiokara, In: 59th Japan Ductile Cast Iron, Association Conference, Tokyo, Japan, 1978, pp. 138-150.

15 J. F. Janowak, P. A. Norton, AFS Trans. 88 (1985) 123.

16 D.A. Hill, D. Nowell, In: Fretting Fatigue ESIS 18, Mechanical Engineering Publications, 1994

17 J.R. Hwang, P.J. Chung, Japanese Society of Mechanical Engineering 13 (1992) 26.

18 P.A.S. Reed, R.C. Thomson, S. James, D.C. Putman, K. K. Lee, S. R. Gunn, Mater. Sci. Eng. A, 346 (2003) 273.

19 B. Stokes, N. Gao, K. K. Lee, P.A.S. Reed, Metall. Trans A, 36 (2005) 977.

20 P.A.S. Reed, M. Joyce, N. Hide, J. Boselli, Report to Federal Mogul, University of Southampton, 1998.

21 R.P. Hockley, D. Thakar, J. Boselli, I. Sinclair, P.A.S. Reed, In: R.K.S. Ravichandran, R. Ritchie, Y. Murakami (Eds.), Small Fatigue Cracks: Mechanics, Mechanisms and Applications, New York, Elsevier, 1999, pp. 49-56.

22. P. M. Scott, T.W. Thorpe, Fatigue and Fracture of Engineering Materials and Structures, 4 (1981) 291.

23 J.S James, Microstructural Modelling of ADI Camshafts, PhD Thesis, Loughborough University, UK, 1999.

24 B. Stokes, Fatigue Analysis of Austempered ductile Iron Suitable for Automotive Camshaft Applications, PhD Thesis, University of Southampton, UK, 2003.

25 G.P. Faubert, D.J. Moore, K.B. Rundman, In: Proceedings AFS World Conference on Austempered Ductile Iron, American Foundrymen's Society, Des Plains, Illinois, 1991, pp. 10-16. 
26 J. Ortiz, A.P. Cisilino, J.L. Otegui, Fatigue Fract Engng Mater Struct. 24 (2001) 591.

27 R.C. Thomson, S. James, D.C. Putman, Materials Science and Technology, 10 (2000) 1412.

28 J.S James, R.C Thomson, Proceedings of Caston, Institute of British Foundrymen, 1998.

29 C.K. Lin, P.K. Lia, T.S. Shih, International Journal of Fatigue, 18 (1996) 297.

30 C.K. Lin, Y.L. Pai, International Journal of Fatigue 21 (1999) 45.

31 G.L. Greno, J.L. Otegui, R.E. Boeri, International Journal of Fatigue 21 (1999) 35.

32 T.L. Anderson, Fracture Mechanics - Fundamentals and Applications, CRC Press, 1994.

33 N. Kamp, M.R. Parry, D.S. Singh, I. Sinclair, Acta Mater 52 (2003) 343.

34 J. Ortiz, A.P. Cisilino, J.L. Otegui, Engineering Analysis with Boundary Elements, 25 (2001) 467.

35 J.W. Hutchinson, Acta Metall. 35 (1987) 1605.

36 W.O. Soboyejo, J.F. Knott, Fatigue and Fracture of Engineering Materials, 14 (1991) 37.

37 W.O. Soboyejo, K. Kishimoto, R.A. Smith, J.F. Knott, Fatigue and Fracture of Engineering Materials and Structures, 12 (1989) 167.

38 C.J. Bayley, R. Bell, International Journal of Pressure Vessel and Piping, 74 (1998) 33.

39 T.J. Marrow, J.Y. Buffiere, P.J. Withers, G. Johnson, D. Engelberg, International Journal of Fatigue, 26 (2004) 717.

40 T. J. Marrow, H. Cetinel, Fatigue and Fracture of Engineering Materials and Structures, 23 (2000) 425.

41 T.J. Marrow, H. Cetinel, M. Al-Zalman, S. Macdonald, P.J. Withers, J. Walton, Fatigue and Fracture of Engineering Materials and Structures, 25 (2002) 635.

42 C.Z. Wu and T.S. Shih, International Journal of Cast Materials Research, 15 (2002) 125.

43 L. Bartosiewicz, A.R. Krause, F.A. Alberts, I. Singh, S.K. Putatunda, Materials Characterization, 30 (4) (1993) 221

44 J. Aranzabal I. Guiterrez, J.M. Rodriguezibabe, J..J. Urcola, Metallurgical and Materials Transactions, 28A, (1997) 1143. 


\begin{tabular}{|l|c|c|c|}
\hline$\sigma_{\max }(\mathrm{MPa})$ & 800 & 700 & 600 \\
\hline No. nodules on crack path at 90\% life & 17 & 16 & 9 \\
\hline $\begin{array}{l}\text { No. nodules on crack path at 90\% life as a function } \\
\text { of crack length (nodules/mm) }\end{array}$ & 6.5 & 5.2 & 2.7 \\
\hline $\begin{array}{l}\text { No. nodules on simulated non-deflected crack as a } \\
\text { function of unit length (nodules/mm) }\end{array}$ & 2.9 & 2.4 & 2.8 \\
\hline $\begin{array}{l}\text { No. nodules decohering ahead of crack tip as a } \\
\text { function of crack length (nodules/mm) }\end{array}$ & 9.6 & 4.9 & 0.8 \\
\hline $\begin{array}{l}\text { Percentage of nodules on crack profile at 90\% life } \\
\text { that were seen to decohere ahead of the crack tip }\end{array}$ & $47 \%$ & $25 \%$ & $14 \%$ \\
\hline
\end{tabular}

Table 1: Summary of the influence of graphite nodules on crack propagation at $90 \%$ life. 
Figure captions

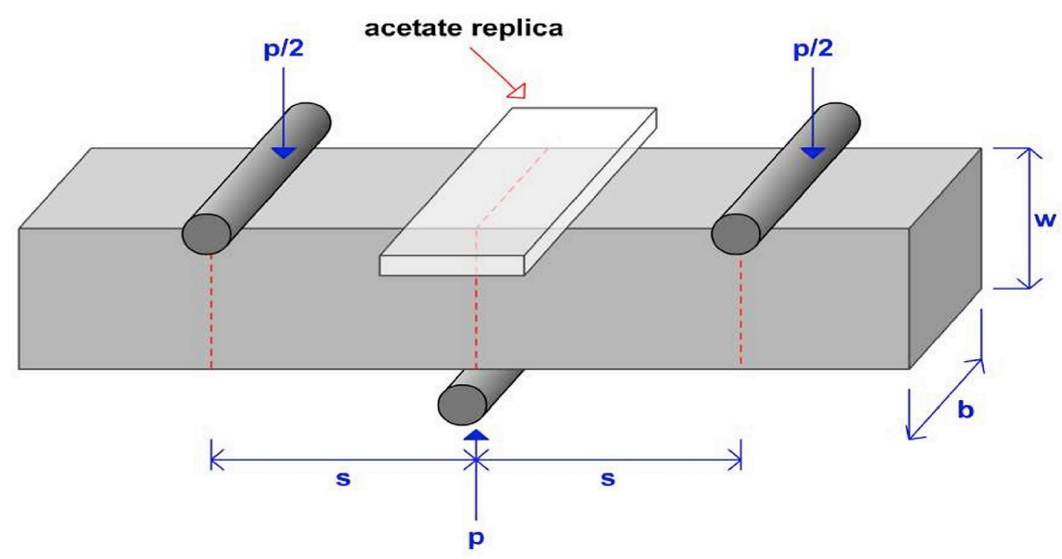

Fig. 1: Three-point bend short crack fatigue test set-up. $\mathrm{P}=$ applied load; $\mathrm{s}=$ separation.

Fig. 1: Three-point bend short crack fatigue test set-up. $\mathrm{P}=$ applied load; $\mathrm{S}=$ separation. 

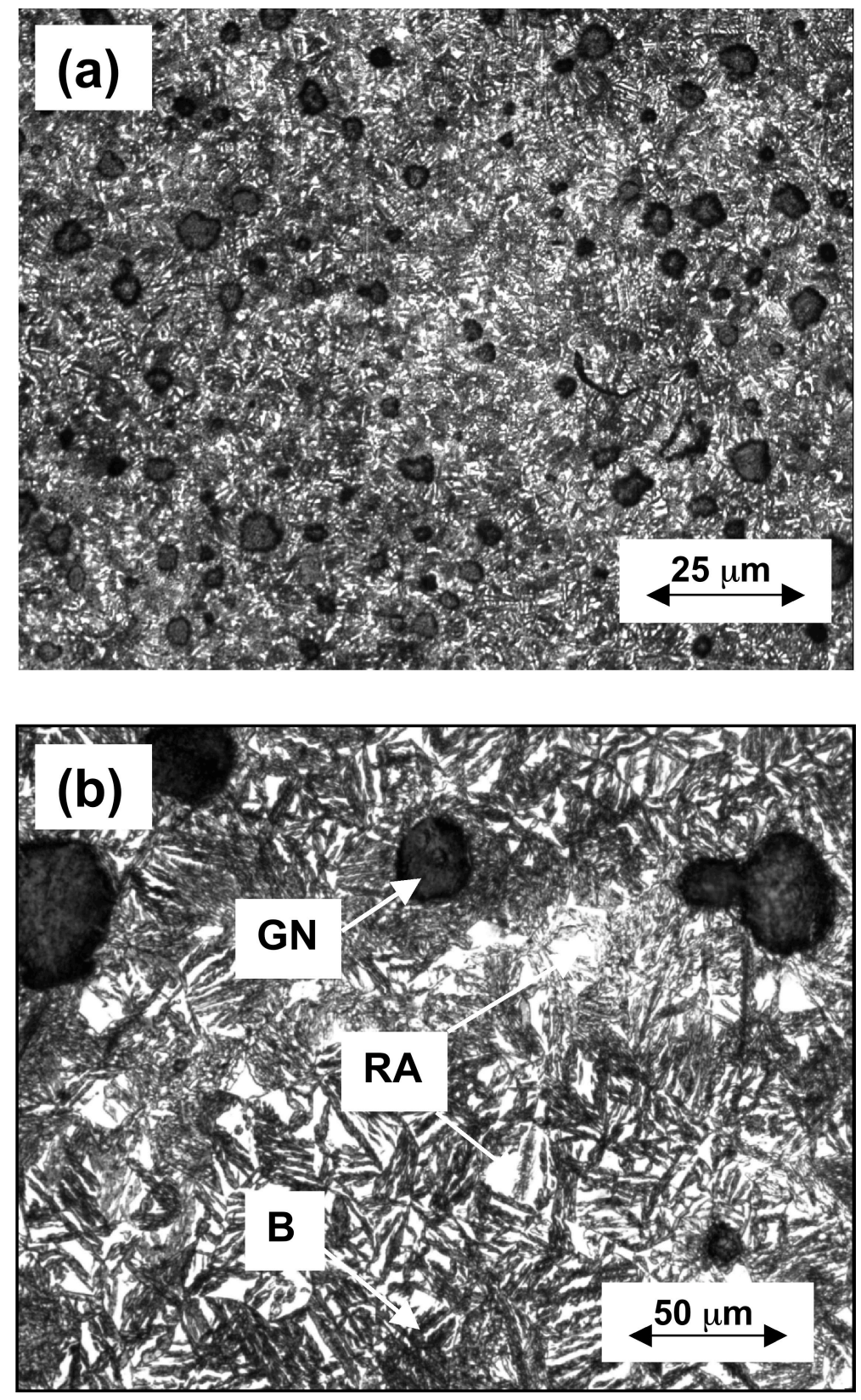

Fig. 2: ADI microstructure, (a) low and (b) high magnification, etched in $2 \%$ Nital.

(GN - Graphite Nodules; RA -Retained Austenite; B - Bainite). 


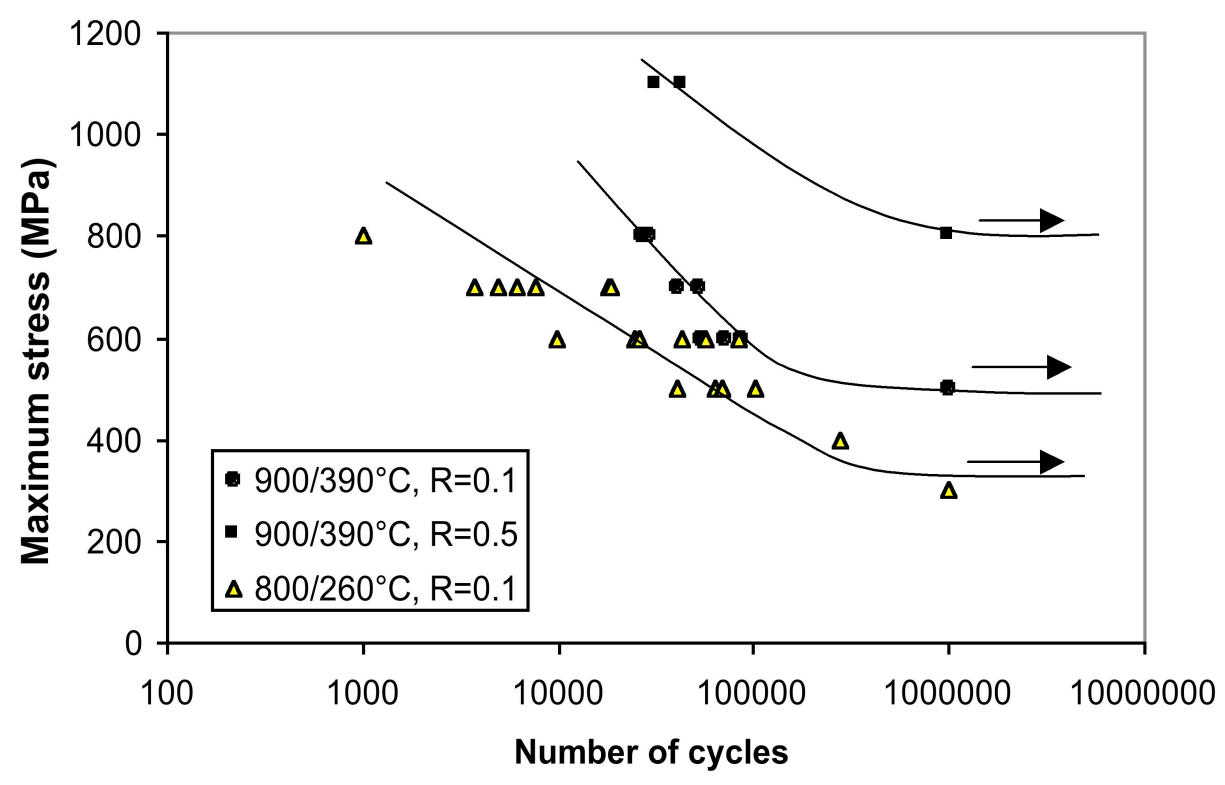

Fig. 3: S-N curve for both heat treatment conditions in terms of the maximum applied stress. 

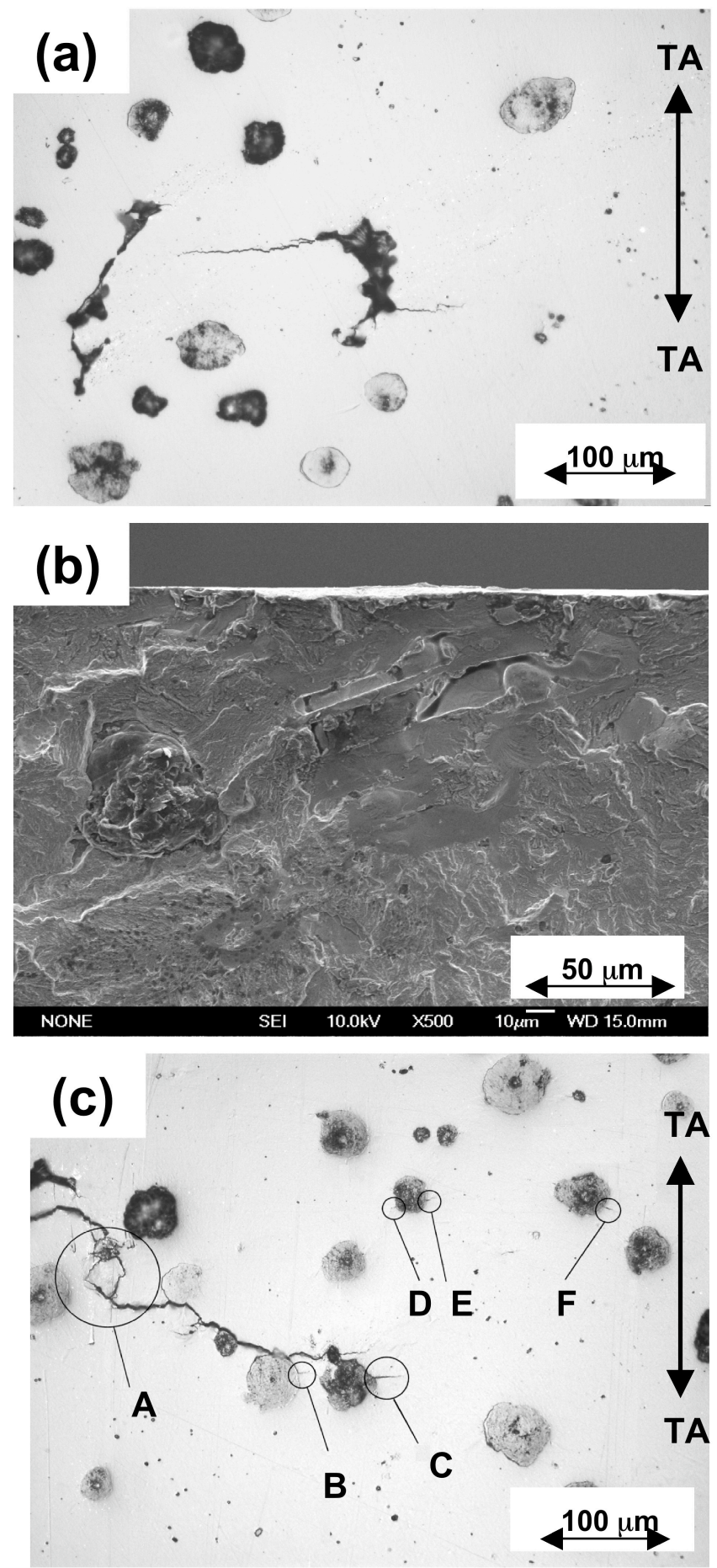

Fig. 4: An example of short fatigue crack initiation at a surface pore (a), at a sub surface pore (b), and crack initiation ahead of advancing dominant crack tip and subsequent coalescence event tested at $\sigma_{\max }=800 \mathrm{MPa}, \mathrm{R}=0.1$ (c). 


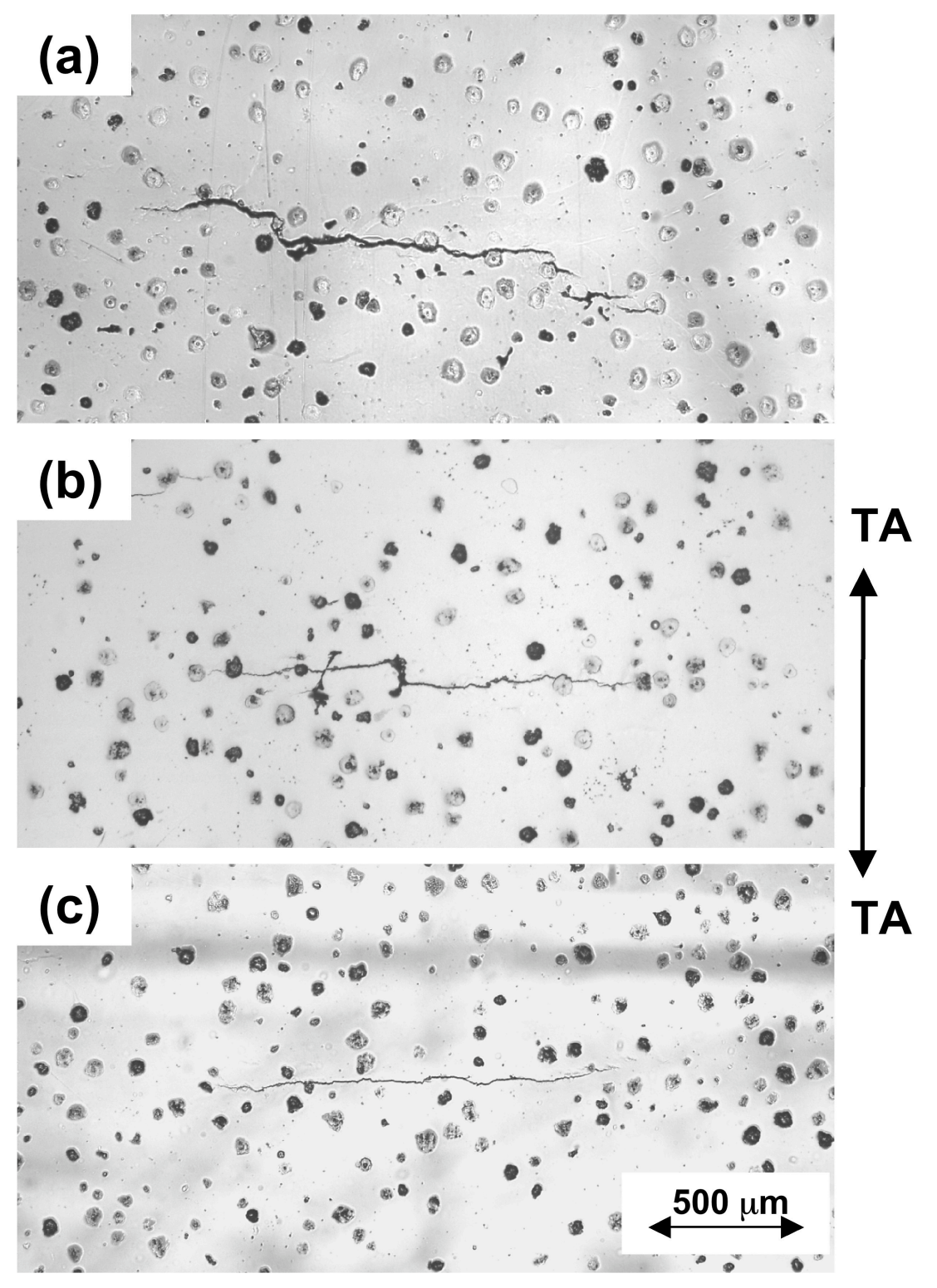

Fig. 5: Dominant crack at $90 \%$ life in specimens tested with $\sigma_{\max }=800(a)$, 700 (b) and $600 \mathrm{MPa}(\mathrm{c}), \mathrm{R}=0.1$. 

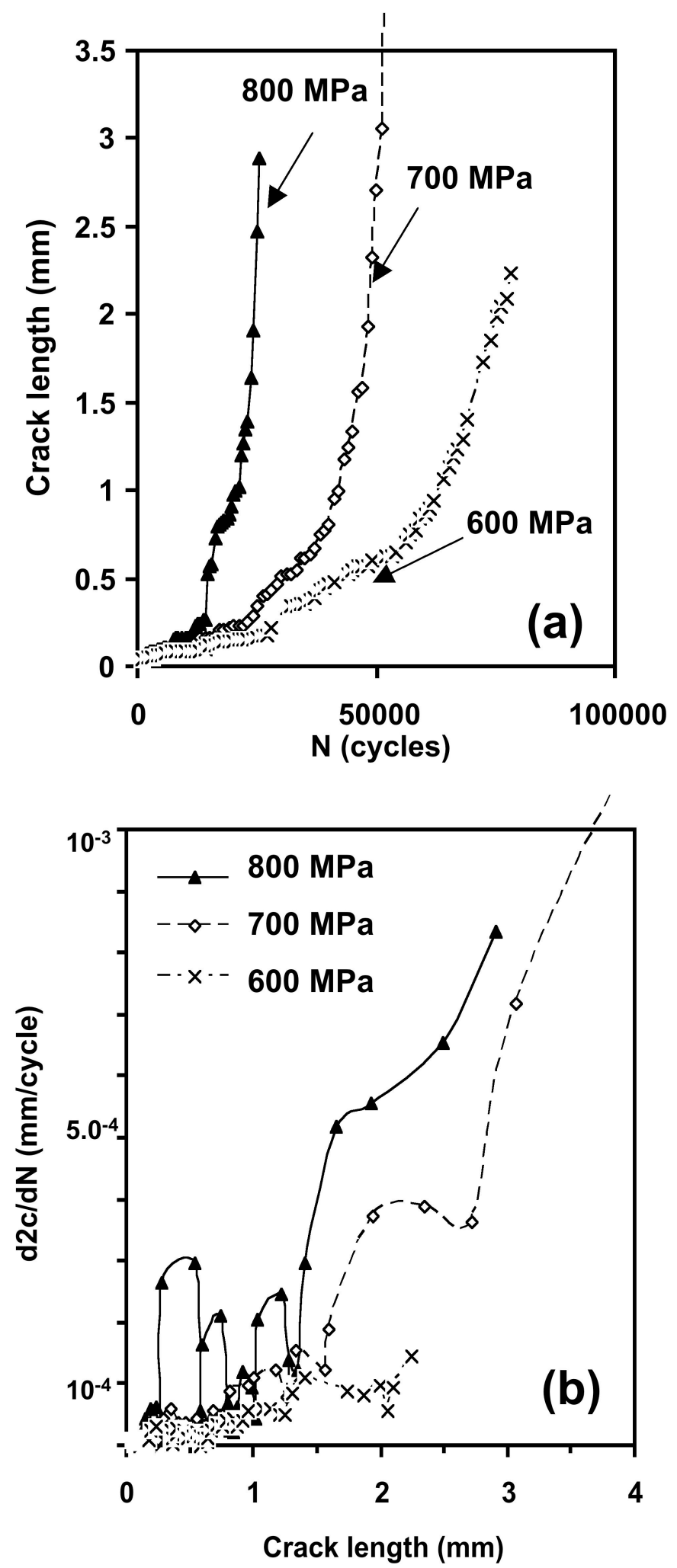

Fig. 6: Crack length plotted as a function of the number of fatigue cycles with different stresses (a), crack growth rate plotted as a function of crack length with different stresses (b). 

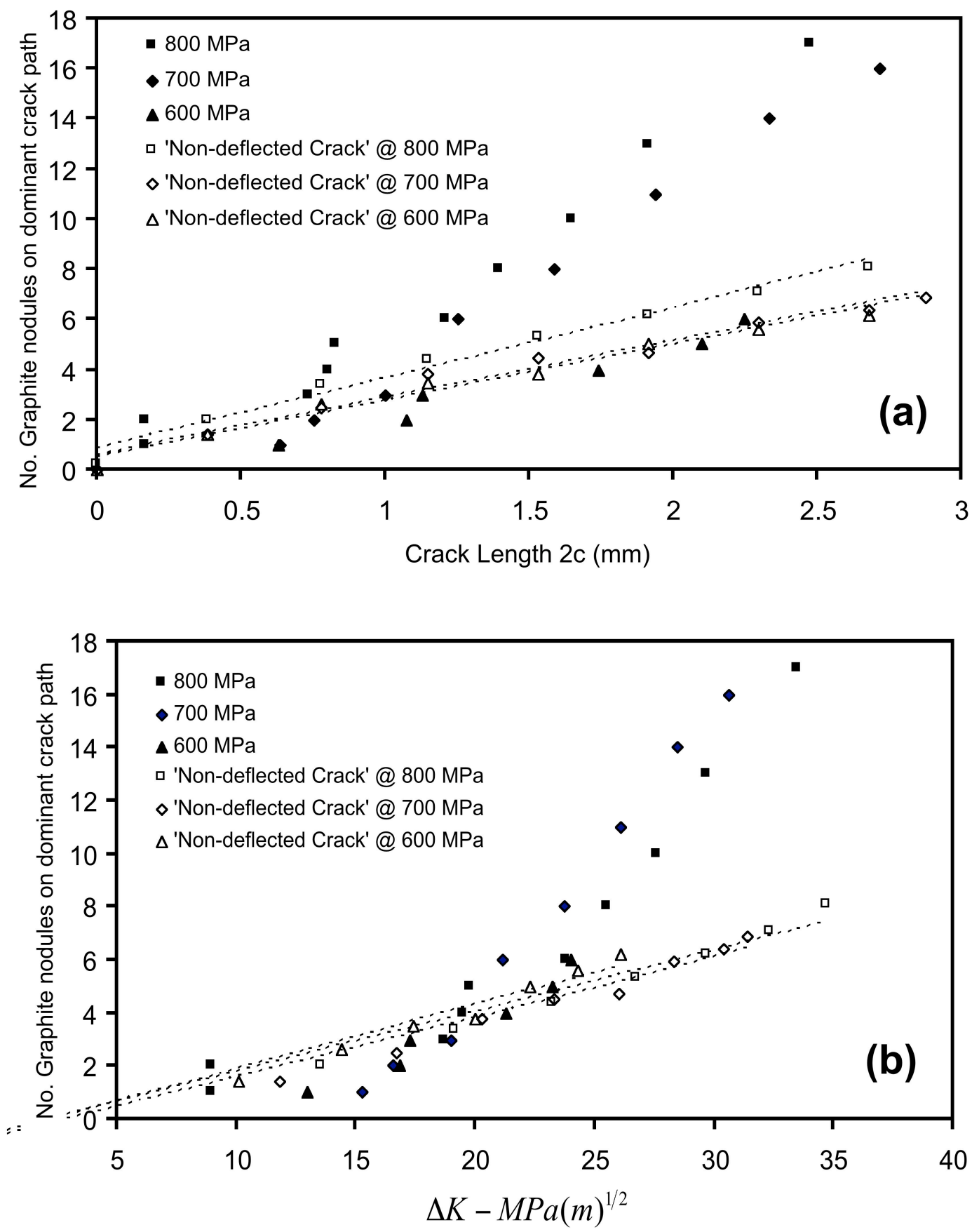

Fig. 7: The variation of the number of graphite nodules on the dominant crack path with crack length (a) and with $\Delta \mathrm{K}(\mathrm{b})$, compared with simulated nondeflected cracks for each stress level. 


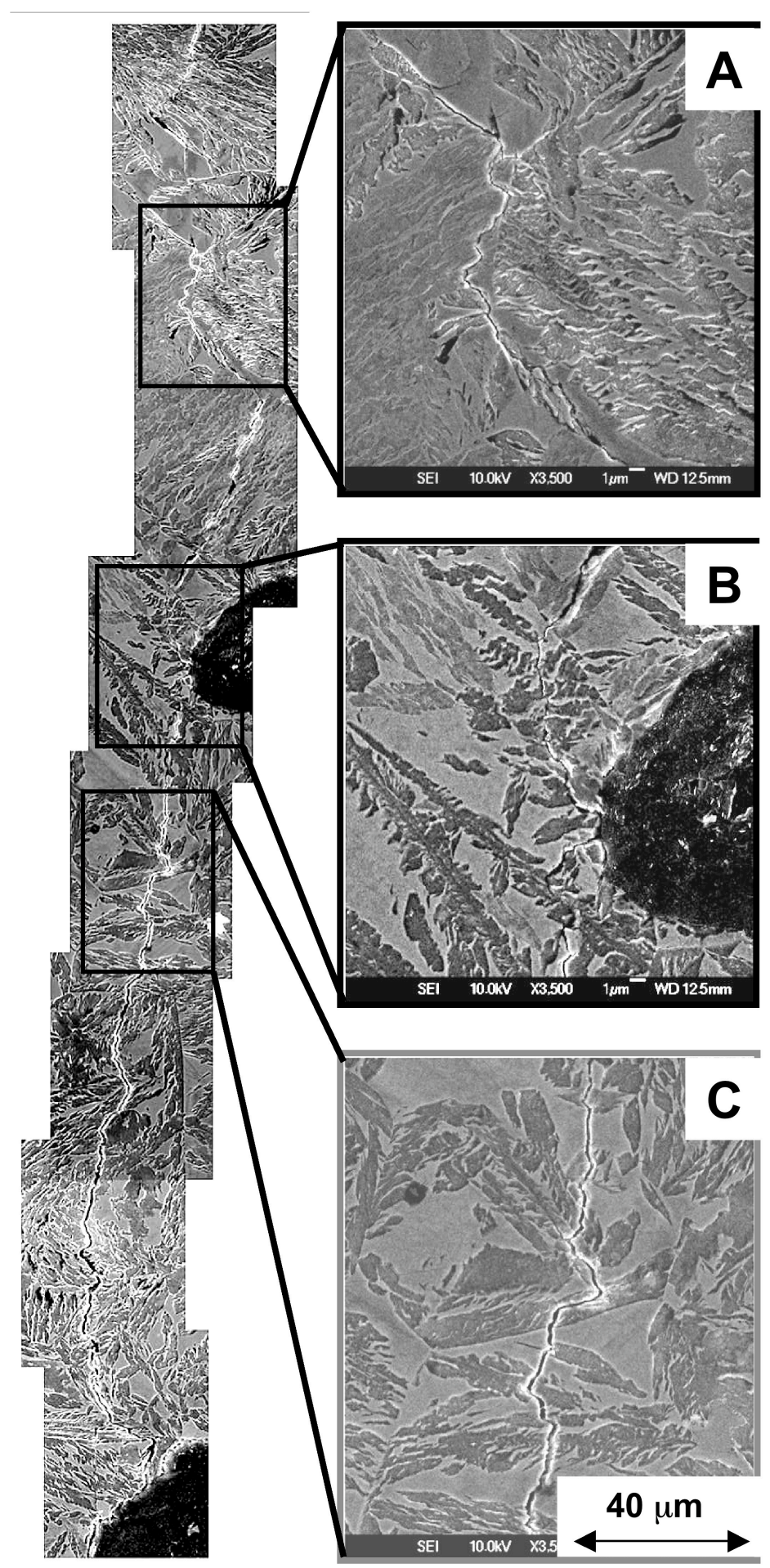

Fig. 8: SEM images showing crack development in interrupted test specimen with $\sigma_{\max }=700 \mathrm{MPa}, \mathrm{R}=0.1$. 

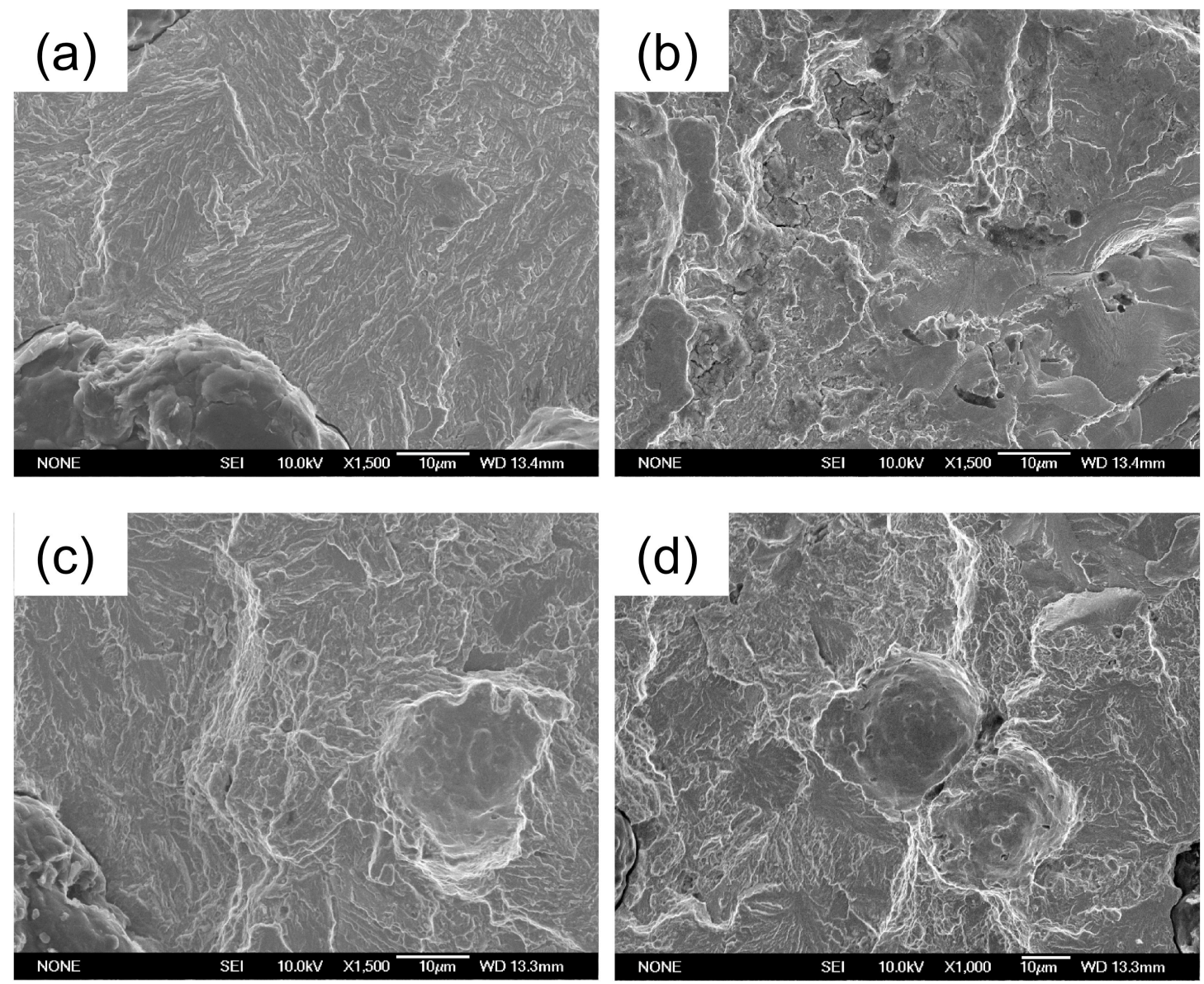

Fig. 9: Fatigue surface of threshold and growth out test specimens. (a) $\Delta K=$ 8; (b) $\Delta \mathrm{K}=15$; (c) $\Delta \mathrm{K}=25$; (d) $\Delta \mathrm{K}=30 \mathrm{MPa} \sqrt{\mathrm{m}}$. 


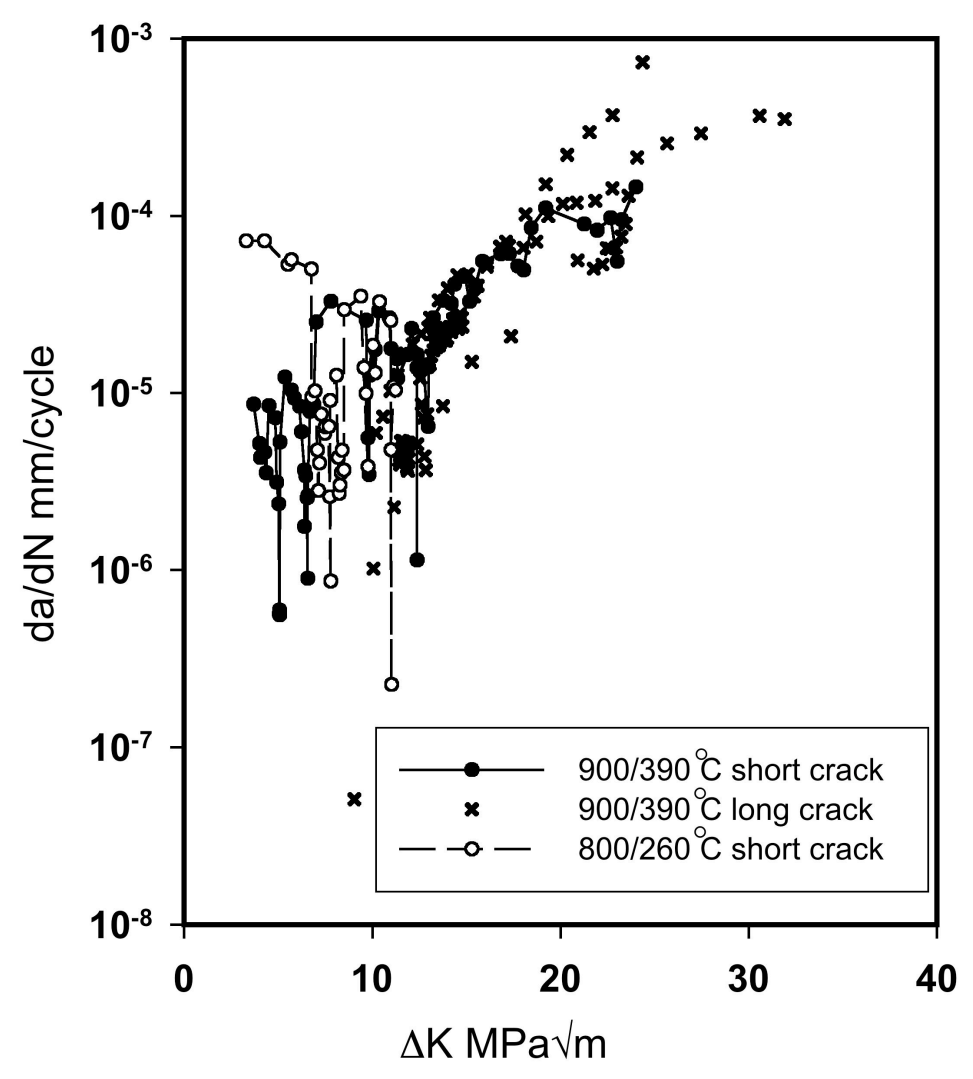

Fig. 10: Comparison of long and short fatigue crack data.

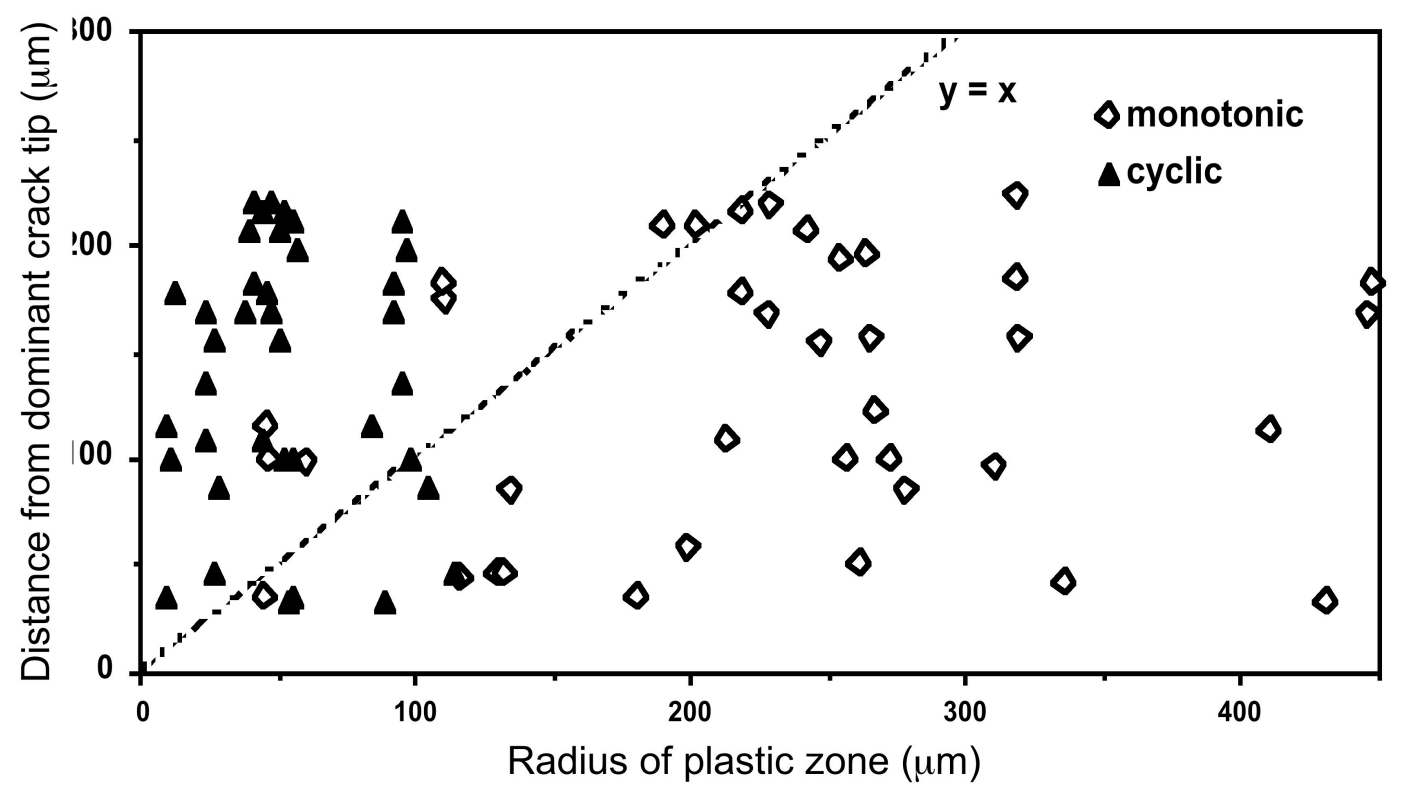

Fig. 11: Comparison of monotonic and plastic crack-tip plastic zone size and proximity of micro-crack initiation events ahead of the advancing dominant 
macro-crack for fatigue crack specimens tested with $\sigma_{\max }=800 / 700, R=0.1$.

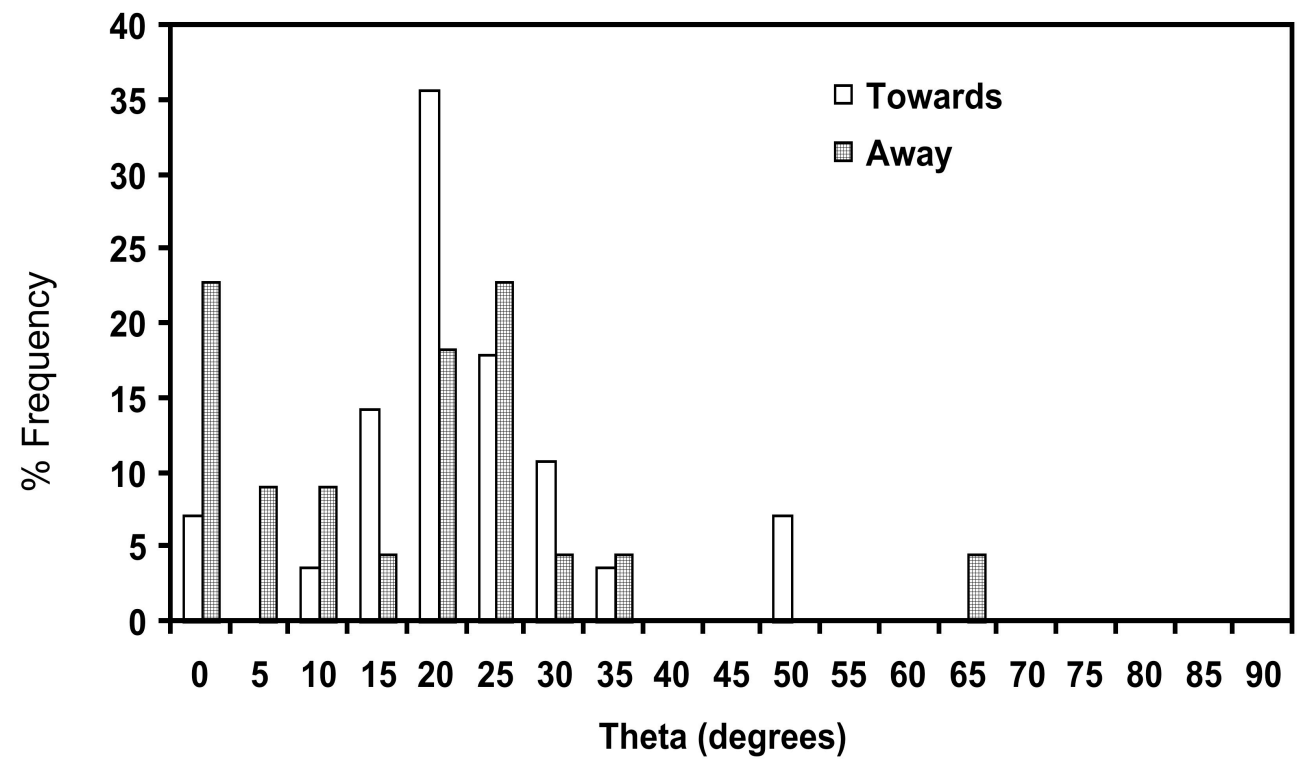

Fig. 12: The orientation of micro-cracks with respect to the graphite nodule.

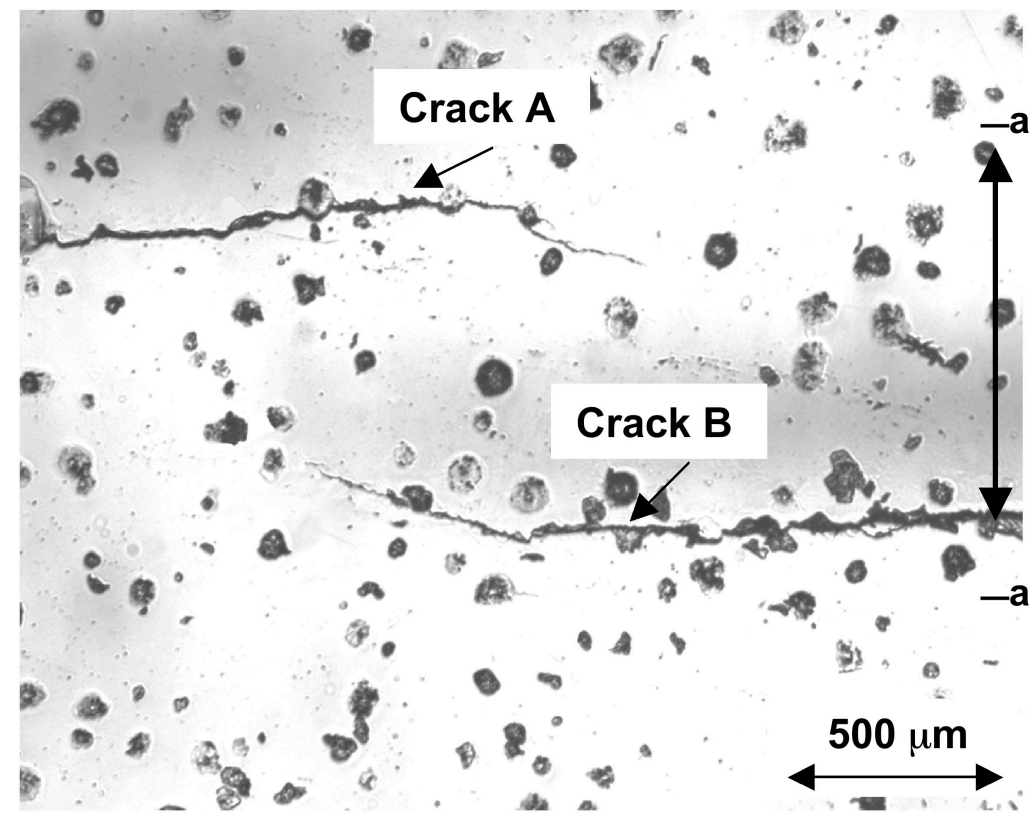

Fig. 13: An example of crack coalescence. 

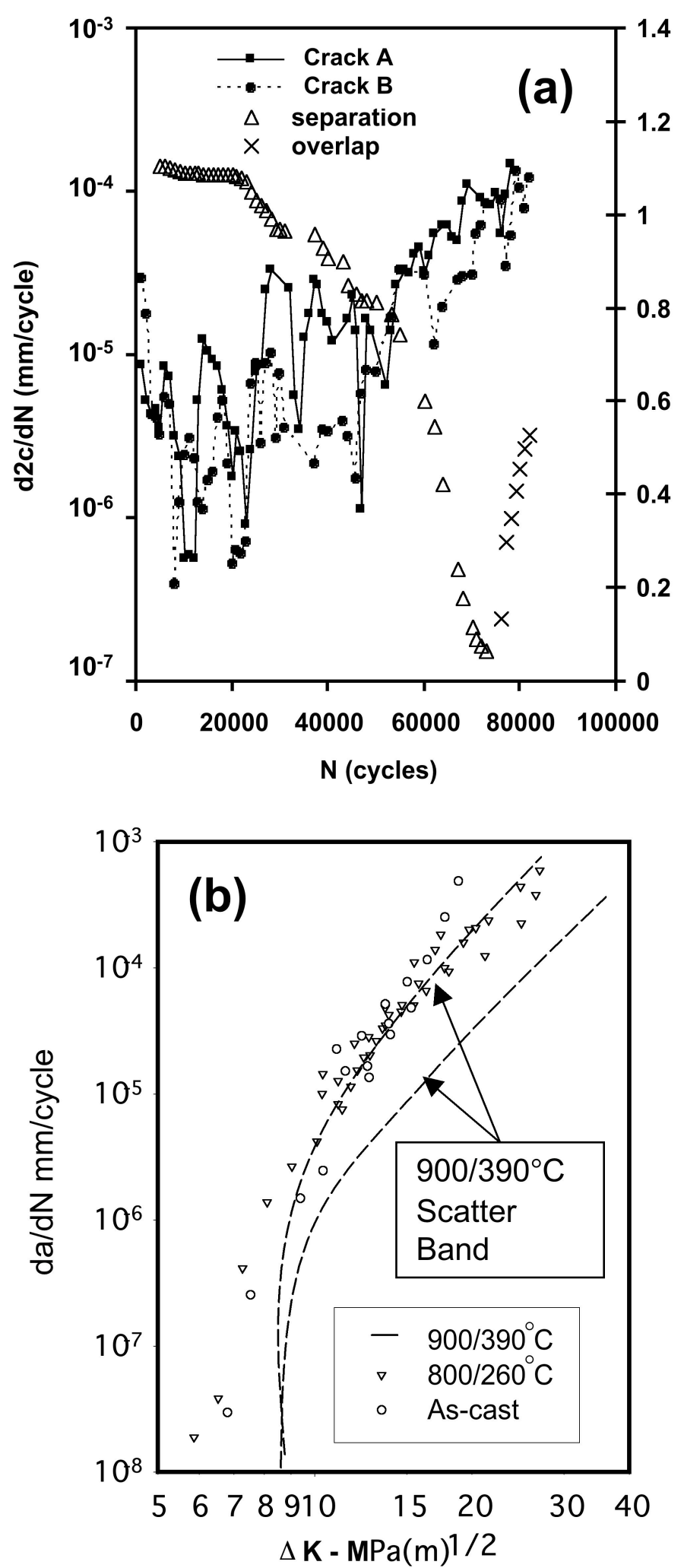

Fig. 14: Crack growth rates (Crack $A$ and $B$ in Fig. 13) and crack-tip separation as a function of number of fatigue cycles (a), and comparison of fatigue crack propagation data from long crack testing (b). 
